\title{
Effect of working pressure and annealing temperature on microstructure and surface chemical composition of barium strontium titanate films grown by pulsed laser deposition
}

\author{
ZAHRA SAROUKHANI ${ }^{1}$, NEMAT TAHMASEBI ${ }^{2, *}$, SEYED MOHAMMAD MAHDAVI ${ }^{3,4}$ \\ and ALI NEMATI ${ }^{1}$ \\ ${ }^{1}$ Department of Material Science and Engineering, Sharif University of Technology, Tehran 11155-9161, Iran \\ ${ }^{2}$ Department of Basic Science, Jundi-Shapur University of Technology, Dezful 64615-334, Iran \\ ${ }^{3}$ Department of Physics, Sharif University of Technology, Tehran 11155-9161, Iran \\ ${ }^{4}$ Institute for Nanoscience and Nanotechnology, Sharif University of Technology, Tehran 11155-9161, Iran
}

MS received 25 March 2015; accepted 29 June 2015

\begin{abstract}
Barium strontium titanate (BST, $\mathrm{Ba}_{1-x} \mathrm{Sr}_{x} \mathrm{TiO}_{3}$ ) thin films have been extensively used in many dielectric devices such as dynamic random access memories (DRAMs). To optimize its characteristics, a microstructural control is essential. In this paper, $\mathrm{Ba}_{0.6} \mathrm{Sr}_{0.4} \mathrm{TiO}_{3}$ thin film has been deposited on the $\mathrm{SiO}_{2} / \mathrm{Si}$ substrate by the pulsed laser deposition (PLD) technique at three different oxygen working pressures of 100, 220 and 350 mTorr. Then the deposited thin films at 100 mTorr oxygen pressure were annealed for 50 min in oxygen ambient at three different temperatures: 650,720 and $800^{\circ} \mathrm{C}$. The effect of oxygen working pressure during laser ablation and thermal treatment on the films was investigated by using X-ray diffraction (XRD), atomic force microscopy (AFM) and scanning electron microscopy (SEM) analysis methods. X-ray photoelectron spectroscopy analysis was used to determine the surface chemical composition of the samples. The results indicate that the deposited BST film at low working pressure (100 $\mathrm{m}$ Torr) in PLD chamber shows a lower surface roughness than other working pressures (220 and $350 \mathrm{mTorr}$ ). The as-deposited films show an amorphous structure and would turn into polycrystalline structure at annealing temperature above $650^{\circ} \mathrm{C}$. Increase of temperature would cause the formation of cubic and perovskite phases, improvement in crystalline peaks and also result in the decomposition of BST at high temperature (above $800^{\circ} \mathrm{C}$ ). In addition, rising of temperature leads to the increase in size of grains and clusters. Therefore more roughness was found at higher temperatures as a result of a more heterogeneous growth and less tensions.
\end{abstract}

Keywords. Barium strontium titanate; thin film; pulsed laser deposition; ferroelectric.

\section{Introduction}

Perovskite barium strontium titanate (BST) thin films are promising candidates for dynamic random access memory (DRAM) owing to their excellent ferroelectric and dielectric properties. DRAM applications of BST thin films require the ferroelectric film to have high dielectric constant, high tunability and low dielectric loss. Also BST materials display a linear relationship between polarization and electric field, they have a low Curie temperature and lack problems related to fatigue and aging. ${ }^{1,2} \mathrm{Ba}_{1-x} \mathrm{Sr}_{x} \mathrm{TiO}_{3}$ has a perovskite structure $\mathrm{ABX}_{3}$, which exhibits complete solid solubility over all compositions, with a cubic structure at room temperature for $0.3<x<1$, becoming tetragonal for $0<x<0.3$. $^{3}$ The tetragonal distortion of BST is associated with the paraelectric-to-ferroelectric transition. For DRAM applications, the cubic form of BST with high dielectric constant is preferred. ${ }^{2}$ Several methods are used for the

\footnotetext{
*Author for correspondence (tahmasebi@jsu.ac.ir)
}

fabrication of BST films. They include RF-sputtering, ${ }^{4,5}$ solgel, ${ }^{6}$ metal organic deposition ${ }^{7}$ and pulsed laser deposition (PLD). ${ }^{8}$ PLD technique has been used extensively as it can maintain the stoichiometry of the target in the deposited film and also has high coverage ability, which both are important in capacitors. ${ }^{9}$ By the PLD method a film with desirable properties could be obtained by controlling the deposition process such as working pressure, substrate temperature and post-annealing temperature. In this work, BST films have been deposited by the PLD method and the effect of working pressure (oxygen gas) and post-annealing temperature on microstructure and surface chemical composition of the BST films have been investigated.

\section{Experimental}

BST films were deposited using the PLD technique from $\mathrm{Ba}_{0.6} \mathrm{Sr}_{0.4} \mathrm{TiO}_{3}$ target. The substrate was $\mathrm{Si}$ (100) and it was cleaned ultrasonically in ethanol. In the PLD system, a high vacuum chamber with a base pressure of $1 \times 10^{-5}$ Torr has been used. BST target was made by $\mathrm{Ba}_{0.6} \mathrm{Sr}_{0.4} \mathrm{TiO}_{3}$ powder 
and shaped into cylindrical sample with diameter of $14 \mathrm{~mm}$ and thickness of $10 \mathrm{~mm}$. The temperature of silicon substrates was kept at $300^{\circ} \mathrm{C}$. The deposited films at this temperature are amorphous. The PLD process was carried out at three oxygen working pressures (purity 99.999\%) 100, 220 and 350 mTorr. It was used 9000 pulses of an eximer laser $\left(\lambda=248 \mathrm{~nm}\right.$, laser energy $300 \mathrm{~mJ}$ pulse $^{-1}$ and R.R. $\left.=10 \mathrm{~Hz}\right)$. To obtain a crystalline structure, the as-deposited films were annealed in oxygen ambient at 650,720 and $800^{\circ} \mathrm{C}$ for $50 \mathrm{~min}$.

The effect of working pressure and thermal treatment on surface morphology of the films was investigated by atomic force microscopy (AFM) (Veeco CP-research model) and scanning electron microscopy (SEM) (TESCAN VEGA model). The crystal structure was characterized by X-ray diffraction (XRD). This analysis was carried out by a Philips Xpert instrument operating with $\mathrm{Cu} K \alpha$ radiation $(\lambda=1.54 \AA)$ at $40 \mathrm{kV} / 40 \mathrm{Ma}$. X-ray photoelectron spectroscopy (XPS) was employed to characterize the surface chemical composition of the films. For the XPS experiment, an $\mathrm{Al}$ anode $\mathrm{X}$-ray source was employed with a concentric hemispherical analyzer (Specs Company, model EA10 plus) to analyse the energy of the emitted photoelectron from the surface. The chamber pressure during the XPS experiment was $7.5 \times 10^{-10}$ Torr. The energy scale was calibrated by adjusting the carbon peak $\mathrm{C}(1 \mathrm{~s})$ at $284.8 \mathrm{eV}$. All the peaks were deconvoluted using an SDP software (version 4.1).

\section{Results and discussion}

\subsection{Effect of working pressure}

XRD analysis was used to investigate the effect of oxygen pressure deposition ambience on crystalline structure of the BST films. XRD data of the as-deposited films revealed an amorphous structure (not shown here). To obtain a crystalline film, the as-deposited films have been annealed at $720^{\circ} \mathrm{C}$ at three different working pressures. Figure 1 shows XRD

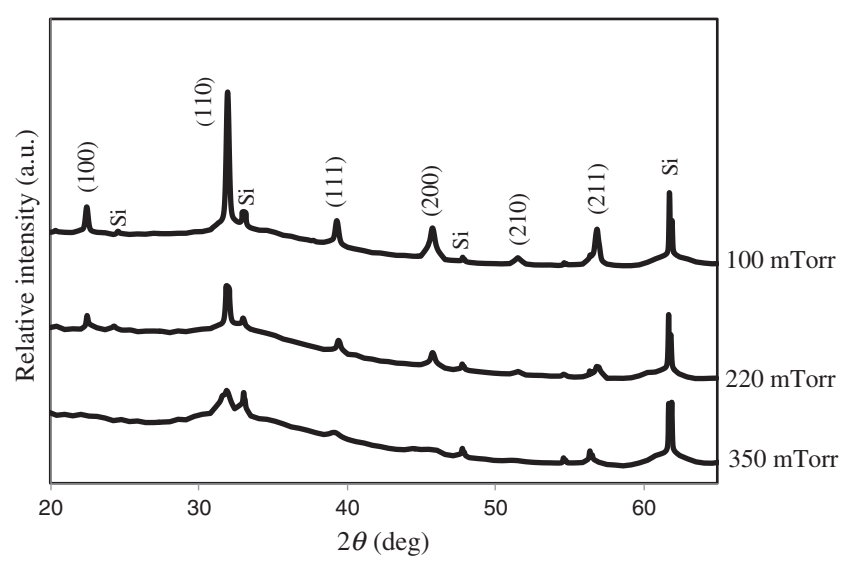

Figure 1. XRD patterns of BST thin films deposited at three different oxygen pressures. patterns of deposited films at 100, 220 and 350 mTorr oxygen pressure. This figure indicates that all films show a polycrystalline structure and that a cubic perovskite phase has been obtained in all three samples. The strongest peak in all samples is related to (110) that is the prominent diffraction peak in the perovskite structure. ${ }^{10}$ From the XRD results, it has also been found that the crystallinity of BST films increases by decreasing the working pressure. In addition, at 350 mTorr $\mathrm{O}_{2}$ deposition ambience, the (100) peak can hardly be observed. The reason is that the (100) are the slowest growing planes in the perovskite structure, because the (100) are closely packed oxygen planes; then these surfaces have the lowest surface energy. ${ }^{11}$ Hence at lower oxygen pressure, the particles that ablated from the target usually have more energy for rearrangement on the substrate surface. In other words, as the oxygen pressure is enhanced, the collisions between ablated particles within plume and oxygen gas also increase, thus the kinetic energy of particles becomes low resulting in a higher intensity of (100) planes for deposited BST films at 100 mTorr oxygen pressure. $^{12}$

Figure 2a shows the SEM image of as-deposited BST film at $100 \mathrm{mTorr}$ oxygen working pressure. As mentioned this micrograph indicates that the as-deposited film has an amorphous structure. To obtain a crystalline film the as-deposited films have been annealed at $720^{\circ} \mathrm{C}$ at different working pressure (100, 220 and 350 mTorr; figure 2b-d). These figures indicate that post-annealing temperature leads to the formation of a polycrystalline structure. It has been observed that the films deposited at a lower working pressure (100 mTorr) have a smooth surface. High working pressure leads
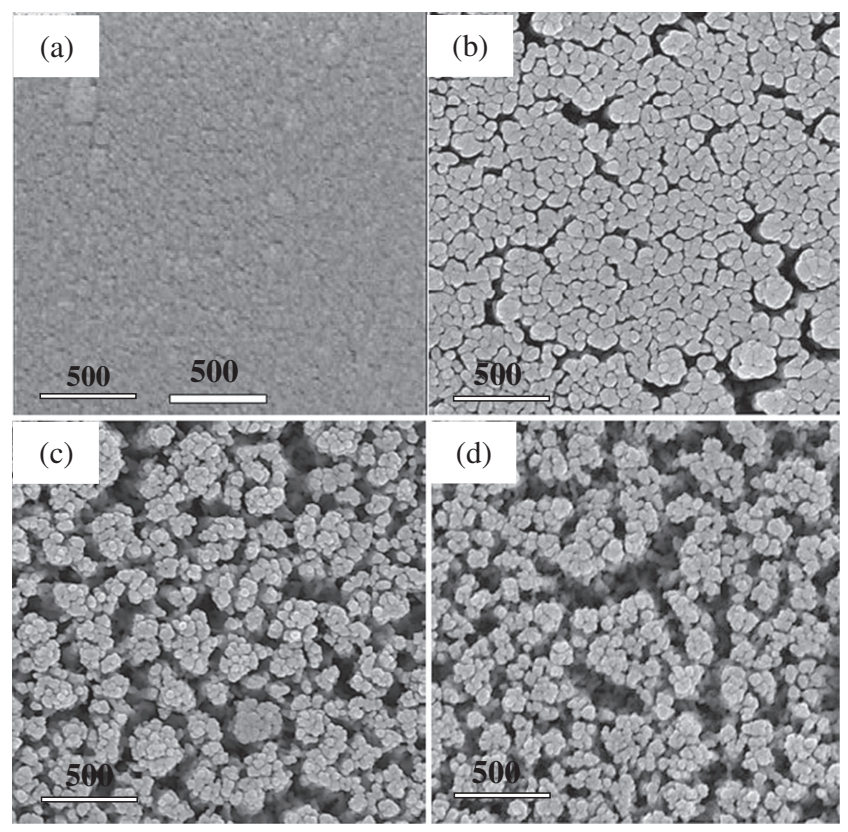

Figure 2. SEM images of deposited films at (a) 100 mTorr without post-annealing and deposited film at (b) 100 mTorr, (c) 220 mTorr and (d) 350 mTorr after post-annealing at $720^{\circ} \mathrm{C}$. 


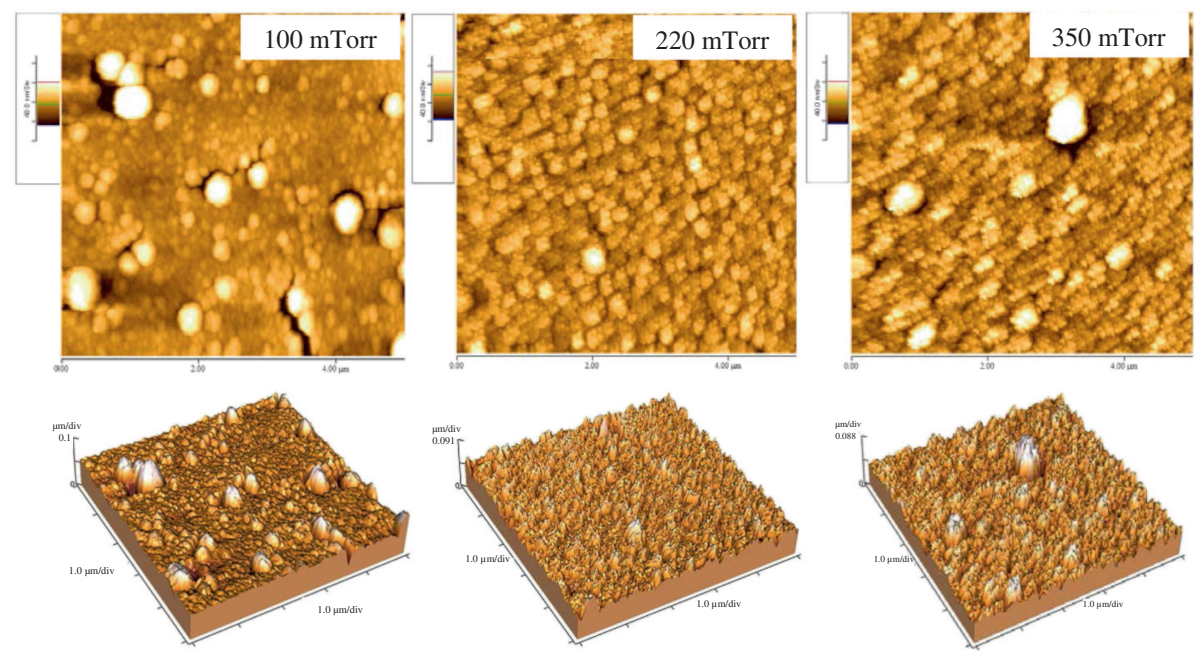

Figure 3. Two- and three-dimensional AFM images of BST thin films deposited at three different oxygen pressures.

Table 1. RMS value of BST thin films at three different oxygen pressures.

\begin{tabular}{lc}
\hline Oxygen pressure (mTorr) & RMS (nm) \\
\hline 100 & 3.640 \\
220 & 6.345 \\
350 & 8.915 \\
\hline
\end{tabular}

to formation of clusters within the gas phase. Such clusters may condense on the film surface, which is not desirable for most applications. This reduces the film quality, damages the microstructure and enhances the surface roughness of the BST films.

Figure 3 shows the two- and three-dimensional AFM images of the BST thin films prepared at different oxygen pressures. As it can be observed, the films have a nanograin size structure, and the root-mean-square (rms) value of surface roughness of BST thin films at three different oxygen pressures are shown in table 1. Less roughness is more appropriate for capacitors because this leads to a better contact between the thin film and electrodes. According to table 1, an increase in roughness with the increase in oxygen pressure could be related to the relaxation of intrinsic stress developed during film deposition. Another reason is that the high working pressure leads to the formation of clusters within the gas phase. In addition, interactions between ablated particles from target and oxygen gas results in kinetic energy loss of particles and reduction in their rearrangement on the substrate. Therefore the ablated particles tend to locate in the vicinity of other particles, and finally lead to increasing the surface roughness. ${ }^{4}$

According to the above results, the deposited film at 100 mTorr oxygen pressure shows a low surface roughness. It is expected that such films which have been formed at mentioned conditions are likely better than the two other

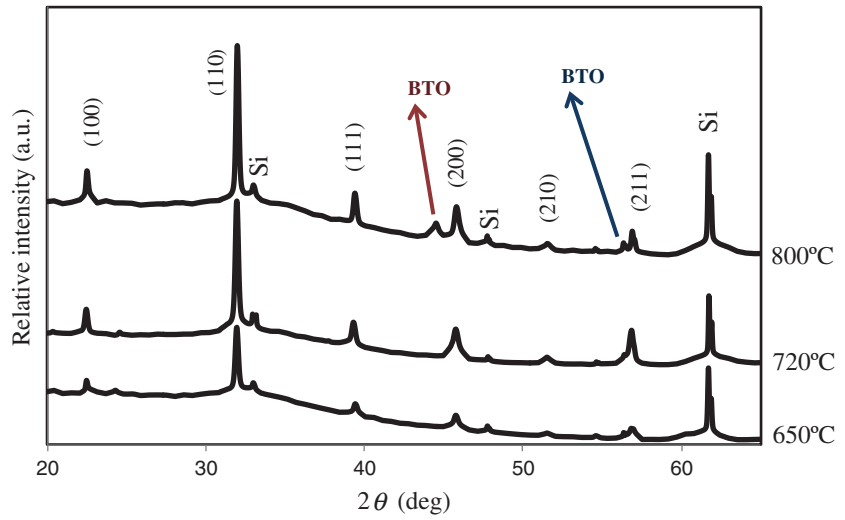

Figure 4. XRD patterns of BST thin films post-annealed at three different temperatures.

types for capacitor applications. Therefore, for investigating the best annealing temperature, the films deposited at 100 mTorr oxygen pressure have been annealed at three different temperatures: 650,720 and $800^{\circ} \mathrm{C}$.

\subsection{Effect of annealing temperature}

Figure 4 shows XRD patterns of annealed films at 650, 720 and $800^{\circ} \mathrm{C}$. As it can be seen in figure 4 , the crystal orientation and crystallinity of the films strongly depends on the annealing temperature, such that as the annealing temperature rises, a better crystalline film is formed. We observed that a cubic perovskite structure of that polycrystalline BST films was typically obtained under all three temperatures. At $650^{\circ} \mathrm{C}$, the strongest peak is related to (110) XRD peaks. Large lattice mismatch between BST thin films and substrate results in less intensity of (100) XRD peaks. ${ }^{13-15}$ As the post-annealed temperature increases from 650 to $720^{\circ} \mathrm{C}$ and $800^{\circ} \mathrm{C}$, both samples display an improvement in (100) 


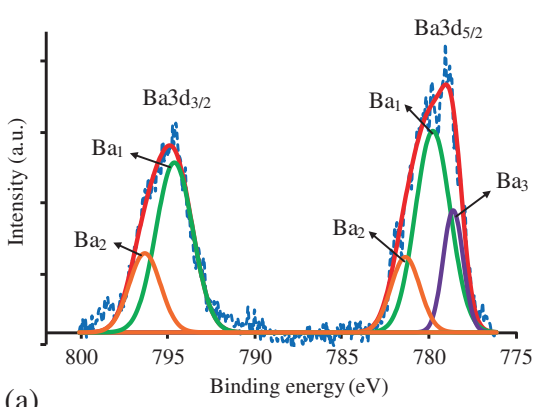

(a)

Figure 5. XPS spectra of $\mathrm{Ba} 3 \mathrm{~d}$ at $(\mathbf{a}) 650^{\circ} \mathrm{C}$, (b) $720^{\circ} \mathrm{C}$ and (c) $800^{\circ} \mathrm{C}$.

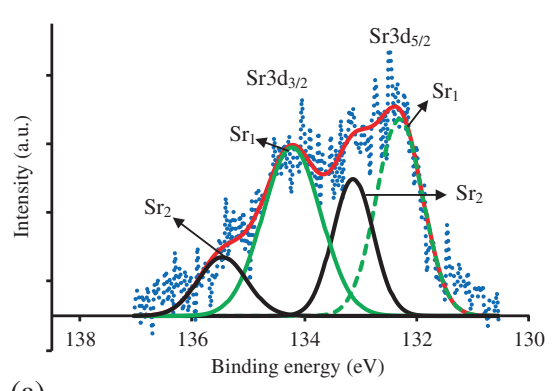

(a)

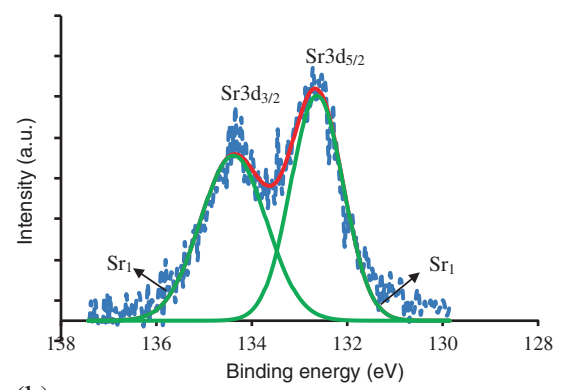

(b)

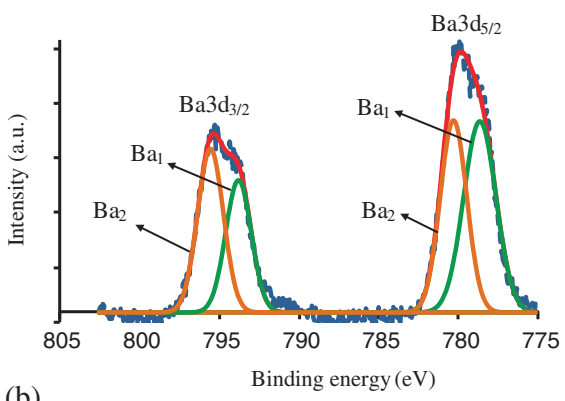

(b)

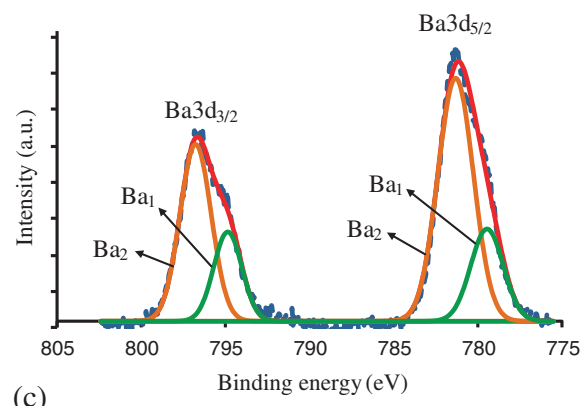

(c)

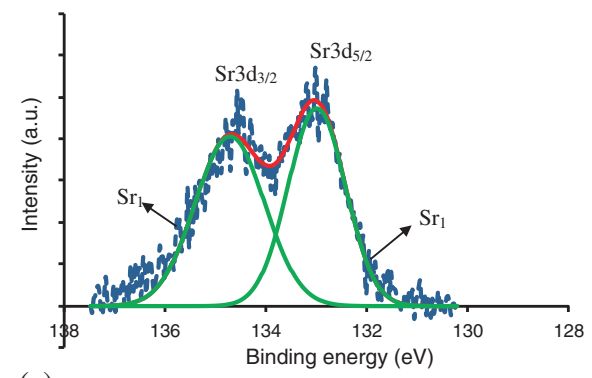

(c)

Figure 6. XPS spectra of $\mathrm{Sr} 3 \mathrm{~d}$ at (a) $650^{\circ} \mathrm{C}$, (b) $720^{\circ} \mathrm{C}$ and (c) $800^{\circ} \mathrm{C}$.

and (110) orientations. With enhancement of the annealing temperature, as it was expected, the amount of crystalline phase (perovskite phase) rises up, but despite the fact that at $800^{\circ} \mathrm{C}$ more crystallinity is observed, the appearance of two new peaks on the XRD pattern (shown by arrow) which are related to the $\mathrm{BaTiO}_{3}$ means the BST thin films are unstable at above $800^{\circ} \mathrm{C}$.

To determine the surface chemical composition of the annealed films at three different temperatures, XPS analysis was used. Figure 5a shows high-resolution XPS spectra of $\mathrm{Ba} 3 \mathrm{~d}$ peak of the BST thin film post-annealed at $650^{\circ} \mathrm{C}$. A fit to the measured data was performed and three separate peaks centred at 779.77, 781.35 and $778.70 \mathrm{eV}$ for $\mathrm{Ba}_{3 / 2}$ and two separate peaks centred at 794.63 and $796.33 \mathrm{eV}$ for

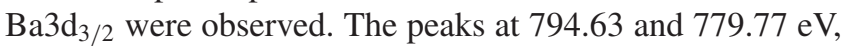
named $\mathrm{Ba}_{1}$, correspond to the $\mathrm{Ba}$ atoms in perovskite structure BST, while the peaks at 796.33 and $781.35 \mathrm{eV}$, named $\mathrm{Ba}_{2}$, correspond to the $\mathrm{Ba}$ atoms in non-perovskite structure BST, which is also called decomposed perovskite structure BST. ${ }^{16}$ The additional peak at lower binding energy of $778.61 \mathrm{eV}$ (named $\mathrm{Ba}_{3}$ ) could be caused by weaker $\mathrm{Ba}-\mathrm{O}$ bonds related to oxygen deficiency. ${ }^{11,17-19}$ This strong $\mathrm{Ba}_{3}$ peak confirms the existence of oxygen deficiency in the film. It has been reported that oxygen vacancies on BST films have a negative effect that causes a high leakage current of Pt/BST/Pt capacitors. ${ }^{20}$ Figure $5 \mathrm{~b}$ and $\mathrm{c}$ shows the Ba3d XPS peaks for BST thin film, post-annealed at 720 and $800^{\circ} \mathrm{C}$, respectively. These figures show that after annealing at temperatures above $650^{\circ} \mathrm{C} \mathrm{Ba}_{3}$ peaks disappear. This can be related to the reduction of oxygen vacancies due to the following reaction:

$$
\mathrm{V}_{\ddot{\mathrm{O}}}+2 \mathrm{e}^{-}+\frac{1}{2} \mathrm{O}_{2}=\mathrm{O}_{\mathrm{O}}
$$

On the other hand, at $800^{\circ} \mathrm{C}$ the peak intensity of $\mathrm{Ba}_{1}$ (perovskite structure) has decreased extremely compared to the $\mathrm{Ba}_{2}$ peak (non-perovskite structure) which can be attributed to the formation of barium carbonate. These results confirm that $\mathrm{Ba}$ in $\mathrm{BST}$ thin films are unstable at temperatures above $800^{\circ} \mathrm{C}$, which is in agreement with the aforementioned XRD data.

Figure 6a shows high-resolution XPS spectra of $\mathrm{Sr} 3 \mathrm{~d}$ peaks for post-annealed BST films at $650^{\circ} \mathrm{C}$. The binding energy of $\mathrm{Sr}_{3} \mathrm{~d}_{5 / 2}$ peaks is centred at 133.13 and $132.30 \mathrm{eV}$; combining these peaks with the peaks of $\mathrm{Sr}_{3 / 2}$ (at 135.46 and $134.22 \mathrm{eV}$ ) results a broad peak of the $\mathrm{SrO}$ spectrum. As shown in figure $7 \mathrm{a}$, the $\mathrm{Sr} 3 \mathrm{~d}$ peaks can be fitted with four peaks. The peaks at 134.22 and $132.30 \mathrm{eV}$ are known as $\mathrm{Sr}_{1}$ and correspond to $\mathrm{Sr}$ atoms in perovskite structure BST, while the peaks at 135.46 and $133.13 \mathrm{eV}$ are known as $\mathrm{Sr}_{2}$ and correspond to $\mathrm{Sr}$ atoms in non-perovskite structure BST and can also be related to $\mathrm{Sr} 3 \mathrm{~d}$ peak in $\mathrm{SrCO}_{3} \cdot{ }^{17-21}$ Figure $6 b$ and $c$ shows the Sr3d XPS peaks for post-annealed BST thin films at 720 and $800^{\circ} \mathrm{C}$, respectively. These figures show that after annealing at temperatures above $650^{\circ} \mathrm{C}, \mathrm{Sr}_{2}$ peaks (non-perovskite structure of $\mathrm{Sr}$ ) disappear.

Figure 7a shows high-resolution spectra of O1s XPS peak. The O1s peak is deconvoluted into three components. The 


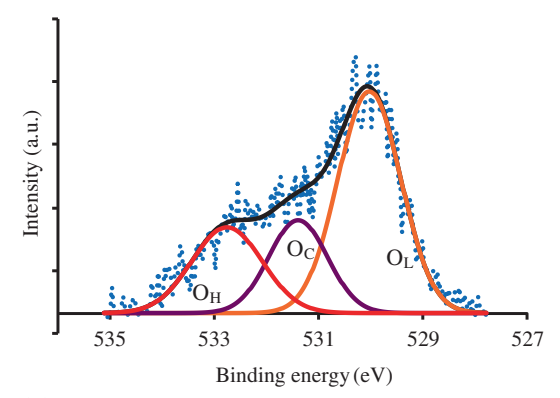

(a)

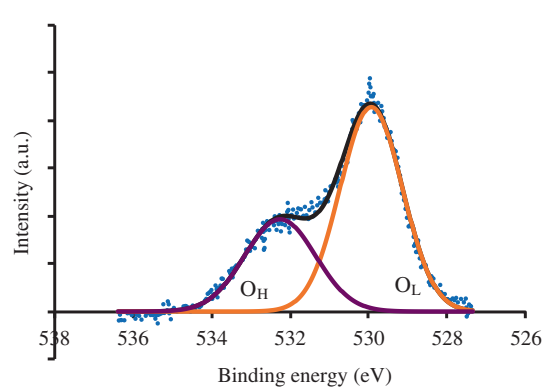

(b)

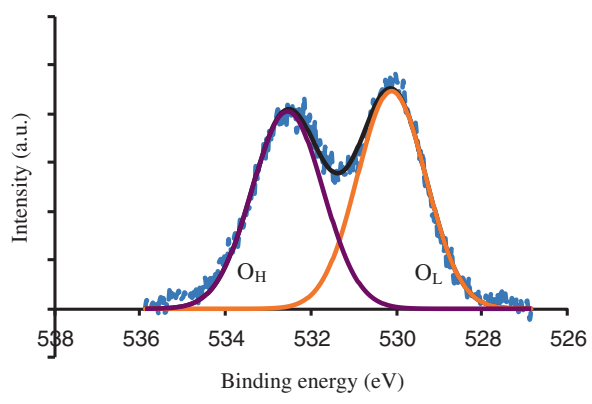

(c)

Figure 7. XPS spectra of $\mathrm{O} 1 \mathrm{~s}$ at (a) $650^{\circ} \mathrm{C}$, (b) $720^{\circ} \mathrm{C}$ and (c) $800^{\circ} \mathrm{C}$.

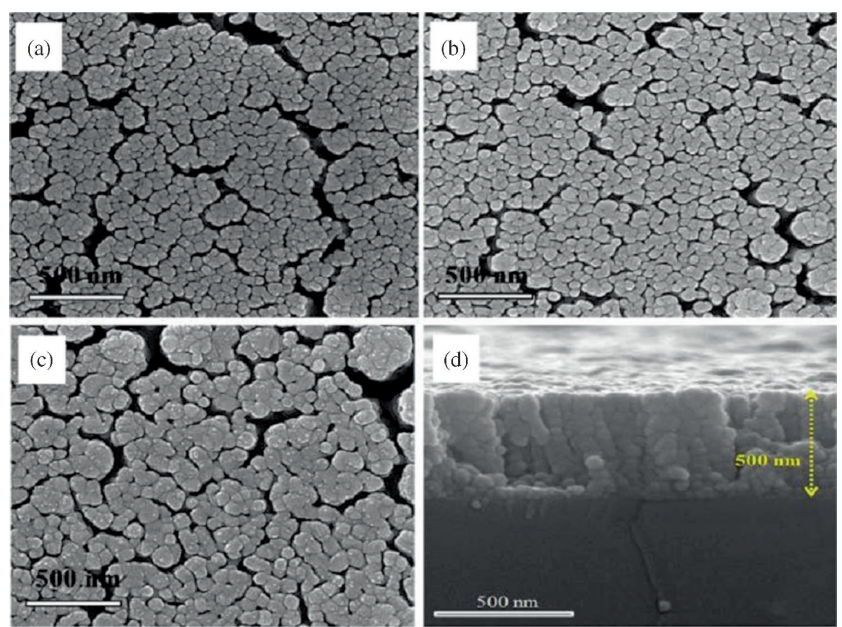

Figure 8. SEM images for BST thin films post-annealed at (a) $650^{\circ} \mathrm{C},(\mathbf{b}) 720^{\circ} \mathrm{C},(\mathbf{c}) 800^{\circ} \mathrm{C}$ and (d) cross-section image of $\mathbf{b}$.

main peak at $530.03 \mathrm{eV}\left(\mathrm{O}_{\mathrm{L}}\right)$ ascribes to oxygen atoms in perovskite structure BST. Two other peaks can be observed at 531.39 and $532.76 \mathrm{eV}$. The chemisorption oxygen $\left(\mathrm{O}_{\mathrm{C}}\right)$ is presented in the range of $\sim 532.5-530.5 \mathrm{eV}$ and corresponds to oxygen atoms in $\mathrm{Ti}_{2} \mathrm{O}_{3}$. In addition, the observed peak at $532.76 \mathrm{eV}\left(\mathrm{O}_{\mathrm{H}}\right)$ is related to oxygen in $\mathrm{OH}$-groups, free oxygen or a contamination. The two latter oxygen species can be possibly related to oxygen deficiency. ${ }^{17,22}$ Figure $7 \mathrm{~b}$ and $\mathrm{c}$ shows the O1s XPS peaks for post-annealed BST thin films at 720 and $800^{\circ} \mathrm{C}$, respectively. These data show that after annealing at temperature above $650^{\circ} \mathrm{C}$, the $\mathrm{O}_{\mathrm{C}}$ peak also disappears. This shows a reduction in oxygen vacancies which are mostly responsible for a high leakage current. $^{21}$

Figure 8 shows SEM images of annealed BST films at different annealing temperatures. According to these images, it can be observed that the average grain size of the polycrystalline films increases with the increase in temperature and due to the sintering, coalescence of small grains to form larger grains is expected. The average grain size for annealed BST thin films have been shown in table 2. Increasing the size of grains means a reduction in the number
Table 2. Average grain size and RMS value of BST thin films post-annealed at three different temperatures.

\begin{tabular}{lcc} 
Annealing temperature $\left({ }^{\circ} \mathrm{C}\right)$ & Average grain size $(\mathrm{nm})$ & $\mathrm{RMS}(\mathrm{nm})$ \\
\hline 650 & 43.90 & 3.500 \\
720 & 57.52 & 3.640 \\
800 & 64.81 & 4.661 \\
\hline
\end{tabular}

of grain boundaries which has a negative effect on dielectric leakage. ${ }^{12}$ In figure $8 \mathrm{~d}$ the cross-section SEM image of deposited film at 100 mTorr is shown, the film thickness is $\sim 500 \mathrm{~nm}$ and the sample has a columnar structure that has already been observed for the deposited films by the PLD method ${ }^{23}$ It is expected that this type of structure is the reason for the enhancement of the films' dielectric constant. ${ }^{24}$

The rms surface roughness of BST thin films annealed at three different temperatures derived from AFM data (not shown here) is shown in table 2. The surface roughness of the polycrystalline BST film increases slightly when the annealing temperature is changed from 650 to $720^{\circ} \mathrm{C}$, whereas there is a sharp increase of surface roughness for annealed films at $800^{\circ} \mathrm{C}$. This sharp increase of roughness could be attributed to non-uniform growth of grains; also above this temperature, abnormal growth is observed. When BST thin films are exposed to an electric field, it is usually considered that higher electric field density exists at the summit of sharp valleys than the smoother surface. Therefore it is expected that the abnormal growth can have a negative effect and lead to the increase in the current leakage.

\section{Conclusion}

In this study, BST films were deposited by the PLD technique. The results showed that oxygen working pressure and post-annealing temperature play crucial roles in the crystalline phase and microstructure of the films. The asdeposited films have an amorphous structure. XRD results of deposited films at three different working pressures after post-annealing at $720^{\circ} \mathrm{C}$ indicate that the crystallinity of 
films increases by decreasing the working pressure (from 100 to 350 mTorr) during laser ablation. It has also been confirmed that by increasing the annealing temperature from 650 to $800^{\circ} \mathrm{C}$ the intensity of crystalline peaks increase, but these films become unstable at/above $800^{\circ} \mathrm{C}$. AFM and SEM pictures indicate that the surface of deposited films at lower working pressure (100 mTorr) is smoother than that others, whereas a raise in oxygen pressure leads to the formation of clusters on the film's surface. It was also observed that the average grain size and the surface roughness of the polycrystalline BST film decreases slightly with decrease in post-annealing temperatures from 800 to $650^{\circ} \mathrm{C}$. XPS results confirm that Ba in BST thin films is unstable at temperatures above $800^{\circ} \mathrm{C}$. On the other hand, by increasing the annealing temperature, oxygen deficiencies can be decreased which are mostly responsible for a high leakage current. In addition, because of the high crystallinity, nanograin size structure and less surface roughness of the deposited films at $100 \mathrm{mTorr}$ working pressure and post-annealing temperature at $720^{\circ} \mathrm{C}$, it is expected that these thin films to be better than those two other types of films for capacitor applications.

\section{References}

1. Wang Y Q, Liang W S, Petrov P K and Alford N M 2011 Mater. Charact. 62294

2. Ahmad A, Goldthorpe I A and Khandani A K 2015 Appl. Phys. Lett. Rev. 2011302

3. Remmel T, Gregory R and Baumert B 1999 International Centre for Diffraction Data

4. Kumar A, Manavalan S G, Gurumurthy V, Jeedigunta S and Weller T 2007 Mater. Sci. Eng. B 139177

5. Padmini P, Taylor T R, Lefever M J, Nagra A S, York R A and Speck J S Appl. Phys. Lett. 753186
6. Saif A A and Poopalan P 2011 J. Mater. Sci. Technol. 27802

7. Zhu H, Miao J, Noda M and Okuyama M 2004 Sens. Actuators A 110371

8. Kocanda M, Mohiudin S F and Abdel-Motaleb L 2012 Cryst. Struct. Theory Appl. 117

9. Bäuerle D 2011 4th ed, Springer Publication, ISBN 978-3-64217612-8

10. Horikawa T, Mikami N, Makita T, Tanimura J, Kataoka M, Kazunao S and Nunoshita M 1993 Jpn. J. Appl. Phys. 324130

11. Gao D, Xiao D, Bi J, Yu P, Yu G, Zhang W and Zhu J U 2003 Mater. Trans. 441320

12. Xing S, Song Z and Lin C 2002 Mater. Lett. 54447

13. Jin H Z, Zhu J, Ehrhart P, Fitsilis F, Jia C L, Regnery S, Urban K and Waser R 2003 Thin Solid Films 429282

14. Tang X G, Xiong H F, Jiang L L and Chan H L W $2005 \mathrm{~J}$. Cryst. Growth 285613

15. Xiaohong Z, Dongning Z, Wei P, Jianguo Z, Xiaowu Y, Jie L, Mingjian Z, Yingfei C, Haiyan T and Xiaoping X 2004 Mater. Lett. 583591

16. Saravanan K V and Raju K C J 2014 Mater. Res. Express 1 015706

17. Liao J X, Yang C R, Tian Z, Yang H G and Jin L 2006 J. Phys. D: Appl. Phys. 392473

18. Craciun V and Singh R K 2000 Appl. Phys. Lett. 7614

19. Lee J H and Rhee S W 1999 J. Electrochem. Soc. 1463783

20. Voigts F, Damjanovíc T, Borchardt G, Argirusis C and Friedrichs W M 2006 J. Nanomater. 631541

21. Joo J H, Seon J M, Jeon Y C, Oh K Y, Roh J S and Kim J J 1997 Appl. Phys. Lett. 703053

22. Tubchareon $\mathrm{T}$, Soisuwan $\mathrm{S}$, Ratanathammaphan $\mathrm{S}$ and Praserthdam P 2013 J. Lumin. 14275

23. Tahmasebi N, Mahdavi S M and Irajizad A 2013 Appl. Surf. Sci. 273261

24. Zhang X Y, Wang P, Xu F and Ong C K 2009 Solid-State Electron. $\mathbf{5 3} 993$ 